\title{
Black carbon, particle number concentration and nitrogen oxide emission factors of random in-use vehicles measured with the on-road chasing method
}

\author{
I. Ježek ${ }^{1}$, T. Katrašnik ${ }^{2}$, D. Westerdahl ${ }^{3}$, and G. Močnik ${ }^{1,4}$ \\ ${ }^{1}$ Aerosol d.o.o., Ljubljana, Slovenia \\ ${ }^{2}$ University of Ljubljana, Faculty of Mechanical engineering, Ljubljana, Slovenia \\ ${ }^{3}$ Cornell University, Sibley School of Mechanical and Aerospace Engineering, Ithaca, New York 14853, USA \\ ${ }^{4}$ Jožef Stefan Institute, Condensed Matter Physics Department, Ljubljana, Slovenia
}

Correspondence to: I. Ježek (irena.jezek@aerosol.si) and G. Močnik (grisa.mocnik@aerosol.si)

Received: 11 May 2015 - Published in Atmos. Chem. Phys. Discuss.: 8 June 2015

Revised: 21 September 2015 - Accepted: 22 September 2015 - Published: 5 October 2015

\begin{abstract}
The chasing method was used in an on-road measurement campaign, and emission factors $(\mathrm{EF})$ of black carbon $(\mathrm{BC})$, particle number $(\mathrm{PN})$ and nitrogen oxides $\left(\mathrm{NO}_{x}\right)$ were determined for 139 individual vehicles of different types encountered on the roads. The aggregated results provide $\mathrm{EFs}$ for $\mathrm{BC}, \mathrm{NO}_{x}$ and $\mathrm{PN}$ for three vehicle categories: goods vehicles, gasoline and diesel passenger cars. This is the first on-road measurement study where BC EFs of numerous individual diesel cars were determined in real-world driving conditions. We found good agreement between EFs of goods vehicles determined in this campaign and the results of previous studies that used either chasing or remote-sensing measurement techniques. The composition of the sampled car fleet determined from the national vehicle registry information is reflective of Eurostat statistical data on the Slovenian and European vehicle fleet. The median BC EF of diesel and gasoline cars that were in use for less than 5 years decreased by 60 and $47 \%$ from those in use for 5-10 years, respectively; the median $\mathrm{NO}_{x}$ and $\mathrm{PN}$ EFs of goods vehicles that were in use for less than 5 years decreased from those in use for 5-10 years by 52 and $67 \%$, respectively. Surprisingly, we found an increase of BC EFs in the newer goods vehicle fleet compared to the 5-10-year old one. The influence of engine maximum power of the measured EFs showed an increase in $\mathrm{NO}_{x} \mathrm{EF}$ from least to more powerful vehicles with diesel engines. Finally, a disproportionate contribution of high emitters to the total emissions of the measured fleet was found; the top $25 \%$ of emitting diesel cars con-
\end{abstract}

tributed 63,47 and $61 \%$ of $\mathrm{BC}, \mathrm{NO}_{x}$ and $\mathrm{PN}$ emissions respectively. With the combination of relatively simple on-road measurements and sophisticated post processing, individual vehicle $\mathrm{EF}$ can be determined and useful information about the fleet emissions can be obtained by exactly representing vehicles which contribute disproportionally to vehicle fleet emissions; and monitor how the numerous emission reduction approaches are reflected in on-road driving conditions.

\section{Introduction}

Traffic is a diverse and important source of air pollution and is complex to describe in terms of per vehicle emissions. The amount of emitted pollutants depends on individual vehicle parameters, the engine type and displacement, the type of exhaust after-treatment system, fuel quality, maintenance status, traffic situations, topography, driver behavior and weather conditions. Owing to the large number of variables, different statistical analyses and measurement approaches have been employed in order to evaluate traffic emissions. These vary in complexity in terms of describing traffic activity and emission factor (EF) determination. Franco et al. (2013) define EFs as being different empirical functional relations of emitted pollutants to the activity that causes them. Most standardized and robust EFs were found to be produced in laboratories using dynamometer tests with prescribed driving cycles. These tests 
can produce the following: (a) aggregated or bag results with respect to the mean speed or some other kinematic parameter (e.g. mean acceleration) of a driving cycle; or (b) instantaneous emission data, where the emissions values measured can be related to recorded instantaneous kinematic or engine covariates (Perrone et al., 2014). But the nature and conditions of the tests limits both the number of vehicles tested and the application to many on-road or so-called "realworld" conditions. In order to validate the emission model predictions and to compare their performance to actual vehicle emissions, "real-world" EF measurement techniques have been developed (Franco et al., 2013). These employ different techniques for measuring numerous vehicles in use in actual traffic situations: the measurements were performed through the use of remote sensing next to the roads, following vehicles on the roads, the use of on-board diagnostics data, or from data taken in tunnels (some of the first such experiments may be found in Bishop et al., 1996; Hansen and Rosen, 1990; Weingartner et al., 1997).

The various "real-world" methods have been described as being less precise than the dynamometer studies because the tests are not as repeatable as their dynamometer counterparts owing to the absence of standard cycles and the presence of additional uncontrolled parameters introducing variability, such as environmental or traffic conditions, driver behavior or highly transient operations (Franco et al., 2013). The on-road measurements have some inherent drawbacks. Two possible shortcomings are that the remote-sensing method can provide only a snapshot of the vehicle emissions and not how the emissions vary during the trip (Franco et al., 2013) and that the on-road chasing method cannot be used in dense traffic situations, where emissions from other vehicles would disturb the background measurements (Ježek et al., 2015; Wang et al., 2011). Their advantage over laboratory measurements is that, over a short period of time, a large number of in-use vehicles can be measured and a representative emission factor distribution for different vehicle categories can be obtained. Most of the previous on-road BC emission factor measurements for individual vehicles were performed on diesel-fueled trucks and on cars with the spark ignition engine, henceforth referred to as gasoline cars (Ban-Weiss et al., 2009; Dallmann et al., 2011, 2012, 2014; Hansen and Rosen, 1990; Wang et al., 2011, 2012). Many of these studies revealed that a small percentage of vehicles - the so-called super emitters contribute disproportionately to total vehicle emissions. Ban-Weiss et al. (2009) demonstrated that $10 \%$ of the trucks contributed $40 \%$ of the $\mathrm{BC}$ and $\mathrm{PN}$ emissions. Wang et al. (2011) showed that, in their measured fleet, $20 \%$ of the trucks contributed $50 \%$ of the carbon monoxide (CO) and $\mathrm{PN}_{0.5}$ emissions, $60 \%$ of the $\mathrm{PM}_{0.5}$ (the particle number concentration - PN; and particulate mass concentration (PM) subscripts denote here the largest mobility diameter $[\mu \mathrm{m}]$ of aerosol particles measured, in this case aerosol particles of $0.5 \mu \mathrm{m}$ and smaller) and over $70 \%$ of black carbon (BC) emissions. Bishop and Stedman (2008) report the same trend for nitrogen oxides $\left(\mathrm{NO}_{x}\right), \mathrm{CO}$ and hydrocarbons (HC). The advantage of individual vehicle measurements over average fleet emission factors, as is often expressed by dynamometer or portable emission measurement system (PEMS) studies, is the ability to detect and express the distribution of emissions from many vehicles as well as to identify "super emitters" and their contributions within the vehicle population, serving as a basis for the implementation of improved emission data, more efficient abatement strategies and monitoring of progress on controls.

The chasing method allows us to capture a range of EF from a single vehicle and to measure the $\mathrm{EF}$ distribution rather than just a single value as is recorded with the stationary method. Depending on engine operation state, each vehicle produces a range of $\mathrm{EF}$ with most values around a representative value (median) and a long super emission tail - the comparison of the chasing method and the stationary method can be found in Ježek et al. (2015). With a single stationary measurement we can capture only a single value of the vehicle's EF distribution and several repetitions of a vehicle would be necessary to obtain that vehicle's EF distribution. We believe that using a single vehicle's EF distribution measured in real driving conditions and using the collective distribution of the vehicle fleet to model traffic emissions could improve model predictions. Knowing the EF representative value and the super emission tails allows quantifying the effect of potential abatement measures, e.g. how changing a driving regime would influence emissions at a certain section of the city. Previous studies using the chasing method for EF measurements in real driving conditions were performed on fleets of buses, light duty vehicles (LGV) with gasoline engines and heavy-goods vehicles (HGV) with diesel engines (Canagaratna et al., 2004; Herndon et al., 2005; Schneider et al., 2008; Shorter et al., 2005; Wang et al., 2011, 2012). Shorter et al. (2005) discuss the effectiveness of the $\mathrm{NO}_{x}$ emission reduction in different engine and exhaust system technologies, which had been introduced to the New York bus fleet. They found that $\mathrm{NO}_{x}$ emissions from diesel and Compressed Natural Gas (CNG) buses were comparable and that diesel hybrid electric buses had approximately one-half the $\mathrm{NO}_{x}$ emissions. They also found that in the group of diesel buses equipped with continuously regenerating technology (CRT), nitrogen dioxide $\left(\mathrm{NO}_{2}\right)$ represented a third of emitted $\mathrm{NO}_{x}$, while in non-CRT buses emissions, the percentage of $\mathrm{NO}_{2}$ was less than $10 \%$. Similar $\mathrm{NO}_{2}$ to $\mathrm{NO}_{x}$ ratios were found by Carslaw and RhysTyler (2013), who used a remote-sensing technique to measure the emissions of almost 70000 vehicles in the United Kingdom (UK), where $30 \%$ of $\mathrm{NO}_{x}$ were emitted as $\mathrm{NO}_{2}$ by Enhanced Environmentally friendly Vehicles (EEV). The EEV is a recommended standard in the European Union for HGVs with lower PM emission values than a Euro VI vehicle but the same $\mathrm{NO}_{x}$ standard as a Euro V.

Wang et al. (2011) measured the EF of BC, CO and $\mathrm{PM}_{0.5}$ on a fleet of 230 trucks and 57 buses in China, and identified 
"heavy emitters" in the road fleet. They found that $5 \%$ of the trucks contributed $50 \%$ of the BC emissions, and $20 \%$ of the trucks contributed $50 \%$ of the $\mathrm{CO}$ and $\mathrm{PM}_{0.5}$ emissions. Furthermore they found that the EFs of trucks registered outside Beijing were significantly higher than those that were subject to the stricter engine and fuel quality standards enforced in Beijing. Because numerous trucks registered outside Beijing operate in the Beijing area, restricting Beijing-registered truck emissions is not sufficient to reduce traffic-related pollution in the city. Their bus fleet measurements showed that replacement of older buses with newer buses (Euro IV and $\mathrm{CNG}$ ) compared to their predecessors (Euro II and Euro I) were indeed an effective way to reduce the emissions of the measured pollutants. In their follow-up study (Wang et al., 2012), they employed the same method on a fleet of 440 onroad trucks, measuring the $\mathrm{EF}$ of $\mathrm{NO}_{x}$ and $\mathrm{BC}$. They found that the measures taken in Beijing were effective for the BC emissions of trucks that were from that area, but they did not observe such a trend for $\mathrm{NO}_{x}$ emissions.

An extensive on-road measurement study was performed in the UK by Carslaw and Rhys-Tyler (2013). They employed a remote-sensing technique to measure the emissions of $\mathrm{NO}, \mathrm{NO}_{2}$ and $\mathrm{NH}_{3}$ on a fleet of almost 70000 individual vehicles which included also vans, passenger cars with a compression ignition engine (henceforth referred to as diesel cars), and gasoline cars. Matching these to vehicle registration data, they found that only gasoline-fueled vehicles had shown an appreciable reduction in $\mathrm{NO}_{x}$ emissions over the past 15-20 years, whereas diesel-fueled vehicles have not. They found that there was an influence of vehicle manufacturer for Euro 4/5 vehicles and that Euro 4/5 diesel vehicles with smaller displacements emit less NO than those with larger displacements. According to the European Automobile Manufacturers' Association (ACEA) the motorization in Europe is increasing for passenger cars and the commercial vehicle fleet - by about $50 \%$ in 2 decades (19902010). Fleet trends show that the percentage of diesel cars is also rising from about $30 \%$ in 2000 to about $60 \%$ in 2011 , and that the most popular passenger cars by segment are small-sized and the lower segment of medium-sized cars which respectively represent 34.2 and $22.1 \%$ of all new cars sold in Europe in 2011 (ACEA, 2012). A slightly smaller percentage of diesel cars $(55 \%)$ was reported by the European Environment Agency (EEA, 2013a) who, in their report titled "Monitoring $\mathrm{CO}_{2}$ emissions from new passenger cars in the EU'. They state that the average car weight was at its highest in the last 9 years, the average engine capacity had decreased by $5 \%$ since 2007 , and, despite of these changes, the improved vehicle technology has led to greater fuel efficiency and lower average $\mathrm{CO}_{2}$ emissions per kilometer traveled (EEA, 2013b). This report was based on data provided by the manufactures who were obliged to measure $\mathrm{CO}_{2}$ emissions using the type approved test cycle (the New European Driving Cycle; NEDC) in laboratory conditions. The statement was refuted by International Council on Clean Transportation in their 2013 white paper (Mock et al., 2013); in which they compared official and "real-world" fuel consumption and $\mathrm{CO}_{2}$ values for cars in Europe and the United States. The report contained an assessment of the results of several on-road driving data sets from various European countries, where they found underestimation by typeapproved measurements relative to on-road $\mathrm{CO}_{2}$ emissions. Namely, in 2001, the discrepancy between the two had been below $10 \%$ and increased to around $25 \%$ by 2011 , with "real-world" emissions being higher than emissions according to type-approval. The same report also clarifies that their analysis does not suggest that manufacturers have done anything illegal. Instead it is suggested that the NEDC was not appropriate to use for indicating fuel consumption as it was originally not designed to measure this, nor was it designed to measure $\mathrm{CO}_{2}$ emissions. Some features of the test procedure can be exploited to influence test results, resulting in unrealistically low $\mathrm{CO}_{2}$ emission levels. These issues are being addressed by the United Nations through the development of a new vehicle test procedure, among other things (Mock et al., 2013). Based on the limited availability of the data that were used in previous studies, we postulate that using on-road emission factors from a representative vehicle fleet could contribute significantly to models' emission predictions. EF determination of a representative on-road sample would include additional sources of variability which can be controlled in the laboratory but not in real-world driving conditions.

$\mathrm{BC}, \mathrm{NO}_{x}$ and $\mathrm{PN}$ are emitted from internal combustion engines and negatively impact people's health. The three pollutants do not have the same formation process (Heywood, 1988; Kittelson et al., 2006). A more detailed description may be found in Sect. S1 in the Supplement. It has been shown that increased $\mathrm{BC}$ concentrations are a better indicator of hazardous health effects of aerosol particle air pollution than the increase in the legislated particle mass concentrations (Janssen et al., 2012); and that it is after $\mathrm{CO}_{2}$ the second most important contributor to global warming (Bond et al., 2013).

The research presented here is aimed to measure realworld BC EF of diesel cars, since there was no previous research reporting BC EF of numerous diesel cars measured individually in real driving conditions. Gasoline cars and goods vehicles were included for comparison purposes. We also measured vehicles' $\mathrm{NO}_{x}$ and PN EFs due to their hazardous effects on health and environment and for the comparison purposes to previous studies. We used the chasing technique (Wang et al., 2011) and the running integration approach to calculate individual vehicles EF (Ježek et al., 2015), because it enables us to measure not only EFs of numerous individual in-use vehicles, but also how their EFs change in time, giving us individual vehicle's EF distribution. We analyze EF distribution within the vehicle category by using the median EF value of individual vehicle's EF distribution and compare our results to those of other chasing and remote-sensing 
studies. We obtained registration information of the chased vehicles to demonstrate the effects of vehicle age, vehicle maximum engine power, the ratio of maximum power to vehicle size, and finally, the contribution of high emitters to the total emissions of our measured fleet. We report the first onroad determination of $\mathrm{BC}, \mathrm{NO}_{x}$ and $\mathrm{PN}$ EFs of passenger cars measured with the chasing method and the first BC EFs of individual diesel cars measured in real driving conditions.

\section{Methodology}

We performed our measurements in December 2011 over the course of 7 days on Slovenian highways and regional roads, measuring predominantly the Slovenian vehicle fleet (photographs from the measurement campaign are presented in Supplement Fig. S1). Slovenia is a country positioned south of the Alps, next to the Adriatic and opening to the Balkan and East European region. Slovenian highways are part of the V. (Venice-Trieste/Koper-Ljubljana-Budapest-Kiev) and X. (Salzburg-Ljubljana-Zagreb-Belgrade-Thessaloniki) trans-European corridors and are thus an important connection between central and east European states, especially for the transport of goods. As a result, foreign vehicles were also encountered and measured in our campaign.

In EF analysis we included any vehicle which emissions and background concentrations we could capture without interference of other on-road vehicles (vehicles that would drive in front of the chased vehicle). The inclusion of the measurement in further analysis was determined on-road and confirmed with video recordings of each chase. For most vehicles we measured the background concentrations before and after the chase, in few instances we used only one measured before or after the chase. On average each chase lasted for 2 and a half minutes, with the shortest chase lasting for $47 \mathrm{~s}$ and the longest for $396 \mathrm{~s}$. The traveling speed was changing within each chasing episode but for most trucks it was between 80 and $90 \mathrm{~km} \mathrm{~h}^{-1}$ and for cars it was between 100 and $130 \mathrm{~km} \mathrm{~h}^{-1}$. In the final analysis we excluded 10 cars because we could not obtain registration information needed to categorize them as a diesel or a gasoline car.

The mobile measurement platform used for the on-road chasing measurements is described in detail in Ježek et al. (2015). We used instruments with high time resolution (1 to $10 \mathrm{~s}$ ) the Carbocap GMP343 (Vaisala) to measure $\mathrm{CO}_{2}$, the Aethalometer AE33 (Aerosol d.o.o.), the Fast Mobility Particle Sizer (TSI), for the on-road campaign we added also a Nitric Oxide Monitor and an $\mathrm{NO}_{2}$ converter (models 410 and 401, 2B Technologies). For the Nitric Oxide Monitor the sampling line was a Teflon tube, while for the rest we used static-dissipative tubing. The instrumental details and measurement uncertainties are summarized in Table 1. The Aethalometer data were compensated for the loading effect using the Drinovec et al. (2015) compensation algorithm. While the size distribution of the exhaust particles change with the engine operation (Ježek et al., 2015; Sharma et al., 2005), a fact that might have implications in the context of the health effects of exhaust particles, Rayleigh-DebyeGans theory (Sorensen, 2001; an example of such calculation can be found in Kim et al., 2015) predicts the mass absorption cross-section independent of the size distribution of the fractal aggregates. This is consistent with the near-road observations by Ning et al. (2013).

\subsection{Emission factor calculation}

We calculated the emission factor as the pollutant $(P)$ per $\mathrm{kg}$ of fuel consumed, assuming the equal dilution of all emitted pollutants and complete combustion of the fuel, where almost all of the carbon in the fuel is oxidized to $\mathrm{CO}_{2}$ (BanWeiss et al., 2009; Dallmann et al., 2011; Hansen and Rosen, 1990), the fuel consumption can be estimated by measuring the $\mathrm{CO}_{2}$ emissions.

$\mathrm{EF}_{P}=\frac{\int_{t_{j}}^{t_{i}}\left(P_{t_{j}}-P_{t_{i}}\right) \mathrm{d} t}{a \cdot \int_{t_{j}}^{t_{i}}\left(\mathrm{CO}_{2 t_{j}}-\mathrm{CO}_{2 t_{i}}\right) \mathrm{d} t} \cdot w_{\mathrm{c}}$

The coefficient $a$ in denominator represents the mass ratio between $\mathrm{C}$ and $\mathrm{CO}_{2}: a=12: 44=0.2727$, thus converting the mass concentration of $\mathrm{CO}_{2}$ in Eq. (1) to units of mass concentration of $\mathrm{C}\left(\mathrm{mgCperm}^{-3}\right)$. The carbon fraction in fuel $w_{\mathrm{c}}$ for both gasoline and diesel was set to 0.86 (Huss et al., 2013). The subscripts $t_{i}$ and $t_{j}$ denote the time of the beginning and end of integration step, respectively. $\mathrm{NO}_{x}$ was treated as $\mathrm{NO}_{2}$ equivalent with molar mass $46 \mathrm{~g} \mathrm{~mol}^{-1}$ (USEPA, 2010; Wang et al., 2012). We used the running integration approach with the $10 \mathrm{~s}$ integration step, to obtain individual vehicle's time-dependent $\mathrm{EF}$, and thus its $\mathrm{EF}$ distribution. From the distribution we calculated the median value and used it as the representative EF value for the investigated vehicle.

The running integration approach is described in more detail in Ježek et al. (2015), where the chasing method has been tested on contemporary cars in controlled conditions. The results of the two integration approaches - the bulk integration from the beginning and to the end of the chase (Wang et al., 2011) and running integration, have already been compared in Ježek et al. (2015). Here we again perform the comparison on a larger number of measured vehicles. The regressions between the two methods for all three investigated pollutants $\left(\mathrm{BC}, \mathrm{NO}_{x}\right.$ and $\left.\mathrm{PN}\right)$ are presented in Fig. 1. For all three pollutants the Pearson's $r^{\prime}$ coefficient was at least 0.97 , all three intercepts were close to zero. The bulk integration method gives somewhat larger EFs than the running integration for $\mathrm{BC}$ and $\mathrm{PN}$, while the slope is very close to unity for $\mathrm{NO}_{x}$. Whilst BC and PN bulk integration overestimated the median EF by 9 and $14 \%$ respectively, the bulk integration for $\mathrm{NO}_{x}$ EF underestimated the median EFs by $2 \%$. The slight underestimation of bulk $\mathrm{NO}_{x} \mathrm{EFs}$ was probably because the instrument for $\mathrm{NO}_{x}$ measurements had lower time resolution 
Table 1. Measurement instruments, their time resolutions, sampling flows and measurement uncertainties.

\begin{tabular}{lllll}
\hline Instrumentation & Species measured & Time resolution & Instrument flow & Measurement uncertainty \\
\hline Carbocap GMP343 (Vaisala) & $\mathrm{CO}_{2}$ & $2 \mathrm{~s}$ & $7 \mathrm{Lmin}^{-1}$ & $3 \mathrm{ppm}$ \\
Aethalometer AE33 (Aerosol d.o.o.) & $\mathrm{BC}$ & $1 \mathrm{~s}$ & $7 \mathrm{~L} \mathrm{~min}^{-1}$ & $30 \mathrm{ng} \mathrm{m}^{-3}$ \\
FMPS $^{\mathrm{a}}$ (TSI) & $\mathrm{PN}$ & $1 \mathrm{~s}$ & $10 \mathrm{Lmin}^{-1}$ & \pm 10 to $20 \%$ \\
$\begin{array}{l}\text { Nitric Oxide Monitor and an } \mathrm{NO}_{2} \text { con- } \\
\text { verter (models 410 and 401 of 2B Tech- }\end{array}$ & $\mathrm{NO}_{x}$ & $10 \mathrm{~s}$ & $0.7 \mathrm{Lmin}^{-1}$ & $1.5 \mathrm{ppb}$ \\
nologies) & & & & \\
\hline
\end{tabular}

a Particle size range $5.6-560 \mathrm{~nm}$

b The uncertainty of PN measurements is calculated for each particle size stage and varies within different stages. It is dependent on the measurement conditions and PN concentrations.
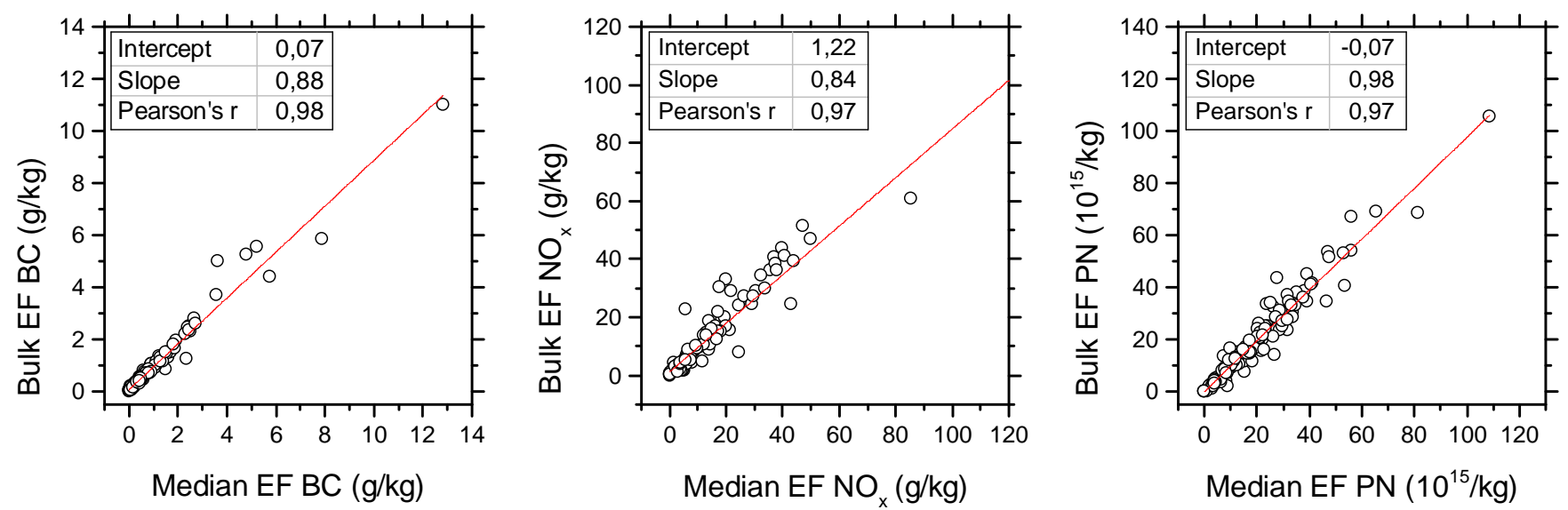

Figure 1. Comparison of two integration approaches to calculate individual vehicle's emission factor (EF). With the bulk integration, the EF is calculated by integrating the plume from the beginning to the end of the chase; the median EF is calculated with the running integration approach with $10 \mathrm{~s}$ integration windows, from the EF distribution the median value is then calculated.

(10s) than other instruments (1 or $2 \mathrm{~s})$, thus super emission peaks were not as clearly resolved as they were for BC and PN.

The uncertainty of the median value, which we here use as the representative $\mathrm{EF}$ value for a single vehicle, was estimated to be $-24 /+26 \%$ (Ježek et al., 2015). This uncertainty is reduced when calculating the fleet EF distribution. The uncertainty of the single measurement depends on the measured $\mathrm{CO}_{2}$ and its signal to noise ratio (Ježek et al., 2015). We constrain the calculation of the time evolving EF when $\mathrm{CO}_{2}$ values are low by using a $10 \mathrm{~s}$ integrating time interval instead of shorter intervals. This smooths out the high engine emission peaks, which are already smoothed out by traveling through the exhaust system and the atmosphere to the measurement instruments (Ajtay et al., 2005), and constrains the calculation error, yet keeping the calculated median value unchanged. The dilution does not affect the measurements of the single vehicle $\mathrm{EF}$ as long as the $\mathrm{CO}_{2}$ increase is above the limit reported in Ježek et al. (2015). We show this in a comparison between a PEMS measurement and a chasing determination of EF (Fig. S2, data from Ježek et al., 2015). The impact of limited number of vehicles was investigated by Ban-Weiss et al. (2009), where they show that sampling $\geq 30$ trucks should be a large enough sample.

\subsection{Vehicle classification and fleet description}

We collected license plate numbers and gained more information on the measured vehicles from their registration certificates. The data provided by the Slovenian Ministry of Infrastructure and Spatial Planning contained information about each vehicle category according to the Directive 2001/116/EC of the European Communities (2002), the fuel used, the date the vehicle first entered into service, curb weight, engine displacement and the maximum net power, where the maximum net power is defined as the maximum value of the net power measured at full engine load (UNECE Regulation No. 85, United Nations, 2013) and the curb weight is the weight of the vehicle without the driver or any other additional load (Regulation No. 540/2014 of the European Parliament, 2014).

For 2011 (the year our measurement study was conducted) we used the Eurostat vehicle fleet statistics (for Europe and Slovenia) and the Slovenian National Interoperability (NIO) portal (http://nio.gov.si/), where we gained detailed 
information on Slovenian car fleet; and compared them to our measured fleet. The Eurostat statistics for cars in Europe include countries that reported not only the total number of cars but also the information on which fuel they used and their respective engine displacements (the countries included are listed in the Supplement Sect. S2). Of the 207185950 passenger cars in-use, $61 \%$ used gasoline fuels and $34 \%$ used diesel.

Our vehicle classification to categories was based on that of vehicle registration information, according to the Commission Directive 2001/116/EC (European Communities, 2002). In Europe vehicles with more than four wheels are organized according to their purpose to categories $\mathrm{M}, \mathrm{N}$ and $\mathrm{O}$, on the first level. Category $\mathrm{M}$ includes vehicles for the transport of passengers, category $\mathrm{N}$ comprises commercial vehicles for the transport of goods, and category $\mathrm{O}$ includes trailers (and semi-trailers). Further categorization of category $\mathrm{M}$ pertains to the number of passenger seats and the vehicle's maximum allowed weight, whereas the $\mathrm{N}$ and $\mathrm{O}$ categories are further segmented regarding the vehicle's maximum allowed weight. This classification, with further sub categories, is then, among other things, also used for prescribing emission standards to new vehicles. Passenger cars (category M1) and light commercial vehicles weighing less than $1305 \mathrm{~kg}$ (category N1-I) have the same emission standards, even though the corresponding Euro 1 and Euro 2 standards came into force in different years. Light commercial vehicles have two more categories of Emission standards: N1-II (1305-1760 kg); and N1-III (> 1760) together with N2 (light commercial vehicles with a maximum mass exceeding $3500 \mathrm{~kg}$ but below $12000 \mathrm{~kg}$ ). Depending on the vehicle's use, the same vehicle can be registered as an M1 or N1. Similar categorization is used in the Eurostat data. There are also many other classifications of vehicles, that depend mostly on the purpose of their use.

We set up three main categories: diesel cars, gasoline cars and goods vehicles. In the gasoline cars category we included only M1 vehicles with spark ignition engines; in diesel cars category we included M1 cars with compression ignition engine and light goods vehicles categorized as N1; other vehicles categorized as N2, N3, M2 or M3 were all in the goods vehicle category. The categorization is summarized in Table 2, where it is also indicated how it overlaps with the classification in Directive 2001/116/EC.

For some heavy goods vehicles, buses and light goods vehicles, we were unable to obtain the vehicle verification data (foreign vehicles and vehicles for which we were unable to note their license plates). These vehicles were only included in the results when more detailed information (age, engine displacement or power) about the vehicle was not needed and the vehicle's category could be determined solely from their visual appearance. Thus, we kept the heavy goods vehicles and vans for which we did not have registration information but could categorize them as N1, N2 or N3, based on their appearance.

\section{Emission factor measurement results}

Our total vehicle fleet sample was 139 vehicles; it consisted of 75 passenger cars (M1) of which 51 were diesel and 24 gasoline cars; 6 buses (M3); 1 mini bus (M2); 26 light goods vehicles, of which 17 were category $\mathrm{N} 1$ and 8 were category $\mathrm{N} 2$; and 32 heavy goods vehicles (N3). We were unable to obtain the registry data for 2 buses, 4 of the light goods vehicles (2 categorized as N1 and 2 as N2), and 15 of the heavy goods vehicles (N3). The fleet sample is summarized in Table 2 .

We compared our measured fleet composition on the vehicles' age and size with the information on the Slovenian and European vehicle fleet statistics (Sect. 3.1). We present our results as $\mathrm{BC}, \mathrm{PN}$ and $\mathrm{NO}_{x} \mathrm{EF}$ distributions for the vehicle categories and compare them to results of other similar studies in Sect. 3.2. We further demonstrate how the EFs of each group depend on their age, by grouping them according to years when Euro 3 and Euro 4 standards became effective. Even though the purpose of use is indeed important when classifying vehicles; but with such categorization the mechanical features may be overlooked. A single car (for example Renault Kangoo or similar) can be classified as a personal vehicle or a light goods vehicle. To see how mechanical and physical features of the vehicles affect the emissions, we disregarded the purpose-based categorizations and observed the effect of engine maximum net power, and the ratio between engine maximum net power and vehicle mass in Sect. 3.4. In Sect. 3.5 we present the contribution of high emitters to the sampled fleet cumulative emissions.

\subsection{Comparison of sampled vehicle fleet and Eurostat data}

The fleet sample size determines the representativeness of the measured fleet. According to Ban-Weis et al. (2009), about $\geq 30$ trucks should be a large enough sample (presuming that the sampling was indeed random) for the sample mean to equally likely to fall below or above the sample mean. Our category samples were larger than the above threshold for diesel cars and goods vehicles, and very close to the threshold for gasoline cars. This makes us confident that the sample is large enough to be representative of the on-road fleet during the approximate period of the campaign on East-West and North-South trans-European corridors V and X. In order to establish the relationship of our data as representative of the Slovenian and the average European fleet, we used Eurostat data to compare the size and age composition of the three investigated vehicle fleets.

In Sect. 3.1.1 we show a comparison between the European, Slovenian and the campaign passenger car fleets (only M1 vehicles) according to the fuel used, engine displacement and age, and in Sect. 3.1.2 the composition of goods vehicle fleets (N1, N2 and N3) according to their size and age. 
Table 2. Number of vehicle types in the sampled fleet, according their assigned categories.

\begin{tabular}{llccc}
\hline Category & Vehicle type & 2001/116/EC & \# in our fleet sample & \# missing registry information \\
\hline Gasoline cars & Gasoline cars & M1 & 24 & 2 \\
\hline \multirow{2}{*}{ Diesel cars } & Diesel cars & M1 & 51 & 2 \\
& Light goods vehicles 1 & N1 & 17 & 2 \\
\hline \multirow{2}{*}{ Goods vehicles } & Light goods vehicles 2 & N2 & 8 & 2 \\
& Mini bus & M2 & 1 & 15 \\
& Buses & N3 & 32 & 6 \\
\hline
\end{tabular}

Table 3. Passenger car fleets according to the fuel used and engine displacement at the end of the year 2011.

\begin{tabular}{|c|c|c|c|c|c|c|c|c|c|}
\hline \multirow{2}{*}{ Fleet } & \multirow{2}{*}{ Total } & \multicolumn{4}{|c|}{ Gasoline } & \multicolumn{4}{|c|}{ Diesel } \\
\hline & & Of total & $\begin{array}{l}\text { Less than } \\
1400 \mathrm{~cm}^{3}\end{array}$ & $\begin{array}{c}\text { From } 1400 \text { to } \\
1999 \mathrm{~cm}^{3}\end{array}$ & $\begin{array}{c}2000 \mathrm{~cm}^{3} \\
\text { or over }\end{array}$ & Of total & $\begin{array}{l}\text { Less than } \\
1400 \mathrm{~cm}^{3}\end{array}$ & $\begin{array}{c}\text { From } 1400 \text { to } \\
1999 \mathrm{~cm}^{3}\end{array}$ & $\begin{array}{r}2000 \mathrm{~cm}^{3} \\
\text { or over }\end{array}$ \\
\hline Europe & 207185950 & $61 \%$ & $49 \%$ & $44 \%$ & $7 \%$ & $34 \%$ & $5 \%$ & $76 \%$ & $19 \%$ \\
\hline Slovenia & $1089335^{*}$ & $63 \%$ & $61 \%$ & $37 \%$ & $3 \%$ & $36 \%$ & $4 \%$ & $79 \%$ & $17 \%$ \\
\hline Our fleet & 75 & $32 \%$ & $50 \%$ & $42 \%$ & $8 \%$ & $68 \%$ & $0 \%$ & $75 \%$ & $25 \%$ \\
\hline
\end{tabular}

* The Slovenian fleet in Eurostat (total vehicles 1066490 ) slightly differs from the NIO database, which is reported in this table, but overall reports almost the same percentages of the vehicle composition.

\subsubsection{Passenger cars}

From Table 3 we can see that the combination of cars in the European and Slovenian fleets are very similar. The percentage of diesel and gasoline cars in the European fleet is 34 and $61 \%$, while the Slovenian fleet has 36 and $63 \%$ of diesel and gasoline cars, respectively. The engine displacements of diesel or gasoline engines are similar. Both fleets show that most gasoline cars have engine displacements smaller than $1400 \mathrm{~cm}^{3}$ (49 and $61 \%$ for European and Slovenian fleet respectively) and that only a small portion of gasoline cars have an engine displacement larger than $2000 \mathrm{~cm}^{3}$ (7 and $3 \%$ for the European and Slovenian fleets, respectively). Most diesel-powered cars have an engine displacement in the size range of 1400 to $2000 \mathrm{~cm}^{3}$ ( 76 and $79 \%$ respectively); the fewest have an engine displacement smaller than $1400 \mathrm{~cm}^{3}$ (5 and $4 \%$ respectively).

The gasoline and diesel car engine displacement segregation of the campaign fleet is representative of the European and Slovenian fleets, where, again most gasoline cars $(50 \%)$ had engine displacements smaller than $1400 \mathrm{~cm}^{3}$, followed by $42 \%$ of cars with engine displacements in the range of 1400 to $1999 \mathrm{~cm}^{3}$ and the fewest gasoline cars had engine displacements larger than $2000 \mathrm{~cm}^{3}(8 \%)$. For diesel cars, the share was - as in the European and Slovenian fleets largest for 1400 to $1999 \mathrm{~cm}^{3}$ sized engines $(75 \%)$, followed by $25 \%$ of diesel cars with engine displacements larger than $2000 \mathrm{~cm}^{3}$. We did not encounter any diesel cars with engine displacements smaller than $1400 \mathrm{~cm}^{3}$.
European and Slovenian car fleet statistics also compare well if segregated by the age of the passenger cars. From Table 4 we can see that the two have almost the same percentage in all four age groups set by Eurostat; the largest difference between them is only $6 \%$. Most passenger cars in both fleets were in use for 10 years or more (42 and $39 \%$ for the European and Slovenian fleets respectively), followed by the group of cars that was in use for between 5 and 10 years (28 and $34 \%$ respectively), almost $20 \%$ were in use for between 2 and 5 years and about $10 \%$ were in use for less than 2 years.

Our total measured passenger car fleet consisted of somewhat more cars in the ages of 2 to 10 years, and fewer vehicles that were over 10 years than were in the Slovenian and European fleets. Using the NIO database we separated Slovenian diesel and gasoline car fleet using 10, 5 and 2 years in use as delimiters. In Table 4 we can see that we get almost the same percentages in all bins for both diesel and gasoline cars in our measured fleet and the Slovenian car fleet. But because, unlike in European or Slovenian fleet, there were more diesel than gasoline cars in our fleet, and because half of gasoline cars were older than 10 years and only $18 \%$ of diesel cars were in that age group, the age of our total fleet does not match the Slovenian or European total car fleet age distribution.

During our measurements, our prime focus was diesel cars, because they are commonly found in Slovenia and Europe and are the most problematic with regard to emissions of $\mathrm{BC}$ and $\mathrm{NO}_{x}$. We used gasoline cars for the control and heavy goods vehicles for comparison with previous studies 
Table 4. Passenger car fleets according to their age, at the end of the year 2011.

\begin{tabular}{llcccc}
\hline & & 10 years or over & From 5 to 10 years & From 2 to 5 years & Less than 2 years \\
\hline Europe & Total & $42 \%$ & $28 \%$ & $19 \%$ & $11 \%$ \\
\hline \multirow{2}{*}{ Slovenia } & Total & $39 \%$ & $34 \%$ & $18 \%$ & $9 \%$ \\
& Gasoline & $50 \%$ & $25 \%$ & $15 \%$ & $9 \%$ \\
& Diesel & $18 \%$ & $48 \%$ & $23 \%$ & $11 \%$ \\
\hline \multirow{2}{*}{ This study } & Total & $27 \%$ & $47 \%$ & $29 \%$ & $7 \%$ \\
& Gasoline & $50 \%$ & $25 \%$ & $17 \%$ & $8 \%$ \\
& Diesel & $16 \%$ & $49 \%$ & $29 \%$ & $6 \%$ \\
\hline
\end{tabular}

that used similar techniques. There are, therefore, a greater percentage of cars powered by diesel $(68 \%)$ than gasoline $(32 \%)$ in the fleet of this study than there are in Europe or Slovenia in general and therefore the age of our total passenger car fleet does not match the total Slovenian nor European passenger car age groups. By analyzing the age distribution within diesel and gasoline cars separately we have shown that our two subcategories do indeed match the Slovenian fleet from which we sampled from and are thus representative of the Slovenian vehicle fleet, and most likely also for the European car fleet, as the two are very similar.

\subsubsection{Goods vehicles}

The goods vehicles are much more versatile in their purpose and hence the mass they have to carry and power they have to produce. We were able to get the registration information for many of the sampled vehicles (28 out of 47) to identify the technical differences between the vehicles. Below, we show the representativeness of the Slovenian fleet for Europe. Our sample seems big enough to be representative, given the previously published criteria (Ban-Weis et al., 2009).

Eurostat does not report the number of heavy goods vehicles as N1, N2 and N3, rather it reports the number of lorries (defined as: rigid road motor vehicle designed, exclusively or primarily, to carry goods) by their load capacity (defined as maximum weight of goods declared permissible by the competent authority of the country of registration of the vehicle). The data thus include vehicles with a gross weight of not more than $3500 \mathrm{~kg}$ but excludes tow trucks. From Table 5 we can see that lorries with load capacity less than $1500 \mathrm{~kg}$ are most numerous in both Slovenian and European fleet and that the vehicles with load capacity over $10000 \mathrm{~kg}$ are fewest. With Tables 5 and 6 (where we report Eurostat data for the European and Slovenian fleet), we demonstrate that the Slovenian vehicle fleet from which we sampled the most vehicles from is representative of European average both regarding the size segregation and vehicle age. We could not make an indirect comparison of Eurostat data to our sample fleet because we did not get the load capacity reported for most of our measured vehicles, and because the number of license plates we could collect was low. Nonetheless, we used the NIO database and found that in the Slovenian fleet there were $72 \%$ of $\mathrm{N} 3$ goods vehicles weighing less than $12000 \mathrm{~kg}$ that were not road tractors or special purpose vehicles, while in our fleet there were $57 \%$ of such vehicles. We binned the vehicles according to their age: those that were in use for less than 10 years, 5 to 10 , and less than 5 years. The Slovenian fleet consisted of 38, 38 and $24 \%$ vehicles in each categories, respectively, while the measured vehicles consisted of 21, 50 and $29 \%$ respectively. Here the size of the sample was only 14 vehicles for which we had registry information. The discrepancy is larger because of the larger diversity in vehicle size among the goods vehicles than for personal cars, and because our sample size is small.

\subsection{Emission factors distributions and comparison to other studies}

We determined EFs of different type vehicles, grouped them into three categories: gasoline cars, diesel cars and goods vehicles (as described in Sect. 2.2), and present their BC, $\mathrm{NO}_{x}$ and PN EF distributions in Fig. 2. Because the formation paths for the three pollutants differ (see Supplement Sect. S1) and technological solutions for the three vehicle categories differ, their EF distributions also show different tendencies. The median BC EF for diesel cars $\left(0.79 \mathrm{~g} \mathrm{~kg}^{-1}\right)$ is the highest of the three vehicle groups, followed by goods vehicles (median $0.47 \mathrm{~g} \mathrm{~kg}^{-1}$ ) and gasoline cars $\left(0.28 \mathrm{~g} \mathrm{~kg}^{-1}\right)$, where also the lowest BC EFs are to be found. The median of $\mathrm{NO}_{x}$ $\mathrm{EF}$ distribution is highest for goods vehicles $\left(27.71 \mathrm{~g} \mathrm{~kg}^{-1}\right)$, followed by diesel cars $\left(15.43 \mathrm{~g} \mathrm{~kg}^{-1}\right)$, and again lowest for gasoline cars $\left(6.34 \mathrm{~g} \mathrm{~kg}^{-1}\right)$. We can observe similar trends with PN EF distribution - highest median value for goods vehicles $\left(11.49 \times 10^{15} \mathrm{~kg}^{-1}\right)$, followed by diesel cars $(4.4 \times$ $\left.10^{15} \mathrm{~kg}^{-1}\right)$ and gasoline cars $\left(1.95 \times 10^{15} \mathrm{~kg}^{-1}\right)$. The shapes of the PN distributions are different from the shapes of the $\mathrm{NO}_{x}$ EF distributions. $\mathrm{NO}_{x}$ EF distributions have the narrowest range of the three investigated pollutants for all three vehicle groups, while PN EF distributions are broad and in the case of goods vehicles even bimodal. They would remain bimodal even if buses and light goods vehicles (N2) would be excluded from the analysis. 
Table 5. Statistics on lorries weight in 2011 for Europe and Slovenia.

\begin{tabular}{lrcccc}
\hline & Total & $\begin{array}{c}\text { Less than } \\
1500 \mathrm{~kg}\end{array}$ & $\begin{array}{c}\text { From } 1500 \text { to } \\
4999 \mathrm{~kg}\end{array}$ & $\begin{array}{c}\text { From } 5000 \text { to } \\
9999 \mathrm{~kg}\end{array}$ & $\begin{array}{c}10000 \mathrm{~kg} \\
\text { or over }\end{array}$ \\
\hline Europe & 17994007 & $79 \%$ & $14 \%$ & $3 \%$ & $4 \%$ \\
Slovenia & 75508 & $71 \%$ & $14 \%$ & $7 \%$ & $8 \%$ \\
\hline
\end{tabular}

Table 6. Statistics on lorries age in year 2011 for Europe and Slovenia.

\begin{tabular}{lrcccc}
\hline & Total & $\begin{array}{c}\text { Less than } \\
\text { 2 years }\end{array}$ & $\begin{array}{c}\text { From 2 to } \\
\text { 5 years }\end{array}$ & $\begin{array}{c}\text { From 5 to } \\
10 \text { years }\end{array}$ & $\begin{array}{c}10 \text { years } \\
\text { or over }\end{array}$ \\
\hline Europe & 17995713 & $10 \%$ & $20 \%$ & $26 \%$ & $43 \%$ \\
Slovenia & 75508 & $11 \%$ & $25 \%$ & $32 \%$ & $32 \%$ \\
\hline
\end{tabular}

In Table 7 we compare the results of our study to other chasing and remote-sensing studies that measured the same species (Ban-Weiss et al., 2009; Carslaw and Rhys-Tyler, 2013; Dallmann et al., 2011; Hudda et al., 2013; Schneider et al., 2008; Shorter et al., 2005; Wang et al., 2011, 2012). Remote-sensing studies were included because good agreement between the results of the remote-sensing and chasing techniques was found by Ježek et al. (2015), where it has been shown that with multiple measurements of the same vehicle with the stationary method, we can obtain a similar distribution as when measuring the same vehicle with the chasing method, and that the median value of both techniques, is similar. We did not compare our results to other study types such as tunnel measurements, chassis dynamometer tests or measurements with portable emission measurement systems, as they have already been discussed in other studies (e.g. Shorter et al., 2005; Wang et al., 2012).

The BC EF median of goods vehicles we measured $\left(0.47 \mathrm{~g} \mathrm{~kg}^{-1}\right)$ is similar to the mean value of $\mathrm{HGV}$ fleet reported by Dallmann et al. in their 2011 study after additional emission control was implemented $\left(0.49 \mathrm{~g} \mathrm{~kg}^{-1}\right)$; it compares well to the results of Wang et al. (2012), for HGVs from the Beijing area $\left(0.40 \mathrm{~g} \mathrm{~kg}^{-1}\right)$, where there are also more strict emission control standards implemented when compared to surrounding provinces and to the results of Hudda et al. (2013), who report $0.41 \mathrm{~g} \mathrm{~kg}^{-1} \mathrm{BC} \mathrm{EF}$ for high cargo route in California (I-710). While BC EFs of these studies (including ours) agree, $\mathrm{NO}_{x}$ EFs do not. While $\mathrm{NO}_{x}$ EFs were high in the Chinese study (47.3 and $40 \mathrm{~g} \mathrm{~kg}^{-1}$ for Beijing and Chongqing respectively), they were much lower in the two US studies $\left(\sim 15 \mathrm{~g} \mathrm{~kg}^{-1}\right)$. The lower EF for the US studies may be due to a different mix of vehicles due to promotion of the purchase of newer vehicles. The median value of the $\mathrm{NO}_{x}$ EF distribution $\left(27.7 \mathrm{~g} \mathrm{~kg}^{-1}\right)$ observed for goods vehicles lies closer to the average HDV fleet value reported by Dallmann et al. (2011) before the active replacement rule was implemented $\left(25.9 \mathrm{~g} \mathrm{~kg}^{-1}\right)$, and to the results of another US study (Shorter et al., 2005) where they report $\mathrm{NO}_{x}$ EF for buses equipped with CRT $\left(27.8 \mathrm{~g} \mathrm{~kg}^{-1}\right)$. The two European studies (Carslaw and Rhys-Tyler, 2013; Schneider et al., 2008) report similar $\mathrm{NO}_{x} \mathrm{EF}$ for different vehicle types while Schneider et al. (2008) measured 18 trucks in Germany by chasing them on the road, and report $\mathrm{NO}_{x}$ EF of their measured fleet to be $18 \mathrm{~g} \mathrm{~kg}^{-1}$. Carslaw and Rhys-Tyler (2013) report similar values $18.9 \mathrm{~g} \mathrm{~kg}^{-1}$ for vans (N1), but much higher for goods vehicles (average of HGV: $37.88 \mathrm{~g} \mathrm{~kg}^{-1}$ ). The reason only $\mathrm{BC}$ or $\mathrm{NO}_{x} \mathrm{EF}$ between our measured fleet and other studies match may be related to the different ages of the investigated vehicle fleets. We will address this again in Sect. 3.3, where we investigate the dependency of the determined EFs to vehicle age in their respective category.

The $\mathrm{NO}_{x}$ EF values of the gasoline and diesel cars in this campaign (6.3 and $15.4 \mathrm{~g} \mathrm{~kg}^{-1}$ respectively) coincide with those reported by Carslaw and Rhys-Tyler (2013) (5.6 and $17.1 \mathrm{~g} \mathrm{~kg}^{-1}$ respectively). The median $\mathrm{NO}_{x} \mathrm{EF}$ of gasoline cars in this campaign is slightly lower than that reported by the EEA $\left(8.7 \mathrm{~g} \mathrm{~kg}^{-1}\right)$ in Tier I approach of their guide book (EEA, 2013c); while those of diesel cars and LDV in this campaign are slightly higher than the $\mathrm{NO}_{x} \mathrm{EFs}$ in the aforementioned guide book $\left(13.0 \mathrm{~g} \mathrm{~kg}^{-1}\right)$. The goods vehicles' $\mathrm{NO}_{x}$ EFs $\left(27.7 \mathrm{~g} \mathrm{~kg}^{-1}\right)$ from this campaign agree with those reported by Shorter et al. (2005) for CRT (CRT stands for continuous regenerating technology) equipped buses $\left(27.8 \mathrm{~g} \mathrm{~kg}^{-1}\right)$; and to $\mathrm{HGV} \mathrm{NO}_{x}$ EFs $\left(25.9 \mathrm{~g} \mathrm{~kg}^{-1}\right)$ reported by Dallmann et al. (2011) for HGV emissions before vehicles had to be retrofitted with additional exhaust aftertreatment devices. The $\mathrm{NO}_{x}$ EFs of goods vehicles measured in the present campaign are lower than $\mathrm{HGV} \mathrm{NO}_{x}$ EFs reported by Wang et al. (2012) (40.0 and $47.3 \mathrm{~g} \mathrm{~kg}^{-1}$ ), who used the same measurement method; lower than Carslaw and Rhys-Tyler (2013) (39.8 $\mathrm{g} \mathrm{kg}^{-1}$ ) who used a stationary remote-sensing method; and lower than HGV EF reported by EEA $\left(33.4 \mathrm{~g} \mathrm{~kg}^{-1}\right)$. This may indicate either that our goods vehicles sample emitted less per unit of fuel; or that the measurement techniques used produce different results. We have shown in Fig. 1 how using two different integration 
Table 7. Comparison of EF with other similar on-road studies.

\begin{tabular}{|c|c|c|c|c|c|}
\hline Study & Study type & Vehicle type & $\mathrm{EF}$ BC $\left(\mathrm{g} \mathrm{kg}^{-1}\right)$ & EF PN $\left(10^{15} \mathrm{~kg}^{-1}\right)$ & $\mathrm{EF} \mathrm{NO}_{x}\left(\mathrm{~g} \mathrm{~kg}^{-1}\right)$ \\
\hline \multirow[t]{2}{*}{ Shorter et al. (2005) } & Chasing $^{\mathrm{a}}$ & Diesel buses & & & $34.5(8.1-117.1)$ \\
\hline & & CRT & & & $27.8( \pm 6.3)$ \\
\hline Schneider et al. (2008) & Chasing $^{b}$ & $\mathrm{HGV}$ & $0.22 \pm 0.14$ & $8.3 \pm 5.8$ & $18 \pm 14$ \\
\hline Ban-Weiss et al. (2009) & Remote s. ${ }^{\mathrm{a}}$ & $\mathrm{HGV}$ & $1.7(0.1-20)$ & $4.7(0.2-40)$ & \\
\hline \multirow[t]{2}{*}{ Dallmann et al. (2011) } & Remote s. $^{\mathrm{d}}$ & HGV (2009) & $1.07 \pm 0.18$ & & $25.9 \pm 1.8$ \\
\hline & & HGV (2010) & $0.49 \pm 0.08$ & & $15.4 \pm 0.9$ \\
\hline Dallmann (2014) & Remote $s .^{d}$ & $\mathrm{HGV}$ & $0.62 \pm 0.17$ & & \\
\hline \multirow[t]{3}{*}{ Hudda et al. (2013) } & Mobile & LDG & $0.07 \pm 0.05$ & $0.43 \pm 0.26$ & $3.8 \pm 1.4$ \\
\hline & & HDD I-710 & $0.41 \pm 0.21$ & $4.2 \pm 3.4$ & $15 \pm 9.2$ \\
\hline & & HDD freeways & $1.33 \pm 0.33$ & $5.2 \pm 3.1$ & $16 \pm 10$ \\
\hline \multirow[t]{2}{*}{ Wang et al. (2012) } & Chasing $^{\mathrm{c}}$ & HGV Beijing & $0.4(0.2-0.8)$ & & $47.3(38.1-62.5)$ \\
\hline & & HGV Chongqing & $1.1(0.7-1.6)$ & & $40.0(31.7-48.1)$ \\
\hline \multirow{4}{*}{$\begin{array}{l}\text { Carslaw and Rhys-Tyler } \\
\text { (2013) }\end{array}$} & Remote s. $^{\mathrm{e}}$ & Gasoline cars & & & $5.6(1.6-28.1)$ \\
\hline & & Diesel cars & & & $16.37(15.7-21.6)$ \\
\hline & & $\operatorname{Van}(\mathrm{N} 1)$ & & & $18.9(17.6-24.7)$ \\
\hline & & HGV (all) & & & $39.8(36.7-50.6)$ \\
\hline \multirow[t]{4}{*}{$\operatorname{EEA}(2013 c)$} & Emission inventory & Gasoline cars & & & $8.73(4.48-29.89)$ \\
\hline & & Diesel cars & & & $12.96(11.2-13.88)$ \\
\hline & & LGV & & & $14.91(13.36-18.43)$ \\
\hline & & HGV & & & $33.37(28.34-28.29)$ \\
\hline \multirow[t]{5}{*}{ This study } & Chasing $^{\mathrm{c}}$ & Gasoline cars & $0.28(0.15-0.46)$ & $1.95(1.08-4.88)$ & $6.34(3.77-10.6)$ \\
\hline & & Diesel cars & $0.79(0.36-1.36)$ & $4.4(2.62-9.03)$ & $15.43(8.82-22.63)$ \\
\hline & & Goods vehicles & $0.47(0.24-0.72)$ & $11.49(2.55-19.76)$ & $27.71(17.89-38.24)$ \\
\hline & & LGV (N2) & $0.64(0.37-0.96)$ & $16.8(8.22-19.01)$ & $23.16(17.89-27.46)$ \\
\hline & & Buses & $0.4(0.24-0.65)$ & $9.99(1.91-19.23)$ & $55.88(39.09-55.9)$ \\
\hline
\end{tabular}

\footnotetext{
${ }^{\mathrm{a}}$ mean (range); ${ }^{\mathrm{b}}$ mean \pm standard deviation; ${ }^{\mathrm{c}}$ median (1st and $3 \mathrm{rd}$ quartile); ${ }^{\mathrm{d}}$ mean $\pm 95 \%$ confidence interval; ${ }^{\mathrm{e}}$ emission ratios from Carslaw and Rhys-Tyler (2013) paper were converted to EFs using the same molecular weights and carbon fraction as in formula 1, for HGV we take the average of both HGV groups they report HGV(3.5-12 $t$ ) and $\mathrm{HGV}(>12 \mathrm{t})$; presented are average values for all Euro standards in a group, in parenthesis are the smallest and largest mean value of emission standards.
}

approaches yields in up to $16 \%$ different results. Some differences between the studies may arise from using the average value for representation of the vehicle categories $\mathrm{EF}$ instead of the median, which is not as strongly influenced by super emitters as the average.

The weight a truck engine has to pull can change drastically from an unloaded truck to twice or three times its unloaded mass, therefore we would expect its emissions would also change a lot more than we would expect them to change with a passenger car. This is one more variable that would be difficult to monitor under controlled condition protocols.

HGV PN EF from Ban-Weiss et al. (2009) $(4.7 \times$ $10^{15} \mathrm{~kg}^{-1}$ ) and from the study of Hudda et al. (2013) (4.2 and $5.2 \times 10^{15} \mathrm{~kg}^{-1}$ ) coincide with those of here presented diesel cars PN EFs $\left(4.4 \times 10^{15} \mathrm{~kg}^{-1}\right)$; and Schneider et al. (2008), PN EF $\left(8.3 \times 10^{15} \mathrm{~kg}^{-1}\right)$ lie closer to our goods vehicle PN EF median $\left(11.49 \times 10^{15} \mathrm{~kg}^{-1}\right)$. The PN EF is most difficult to determine and compare because it depends on the measurement instrument and sampling conditions. Our measure- ments were conducted while chasing vehicles on highways and regional roads in winter, while others measured EF with a remote-sensing method at the end of a tunnel in summer. Each study used different measurement instruments with a different particle size measurement range.

\subsection{Emission factors and vehicle age}

In this section we have further broken down each of our four vehicle groups to three age subgroups: less than 5 years; 5 to 10 years; and 10 or more years in use. We wanted to observe if newer vehicles showed an improvement in their emissions per unit of fuel burned. The 5- and 10-year limits should roughly separate vehicles in three groups that comply with either the entry of Euro standards 4 or 5 (less than 5-year old vehicles), Euro standard 3 (5-10-year old vehicles), and Euro 2, 1 or pre-Euro vehicles (over 10-year old group). A clear separation between vehicles compliant Euro standards cannot be made based solely on the date the vehicle was put 


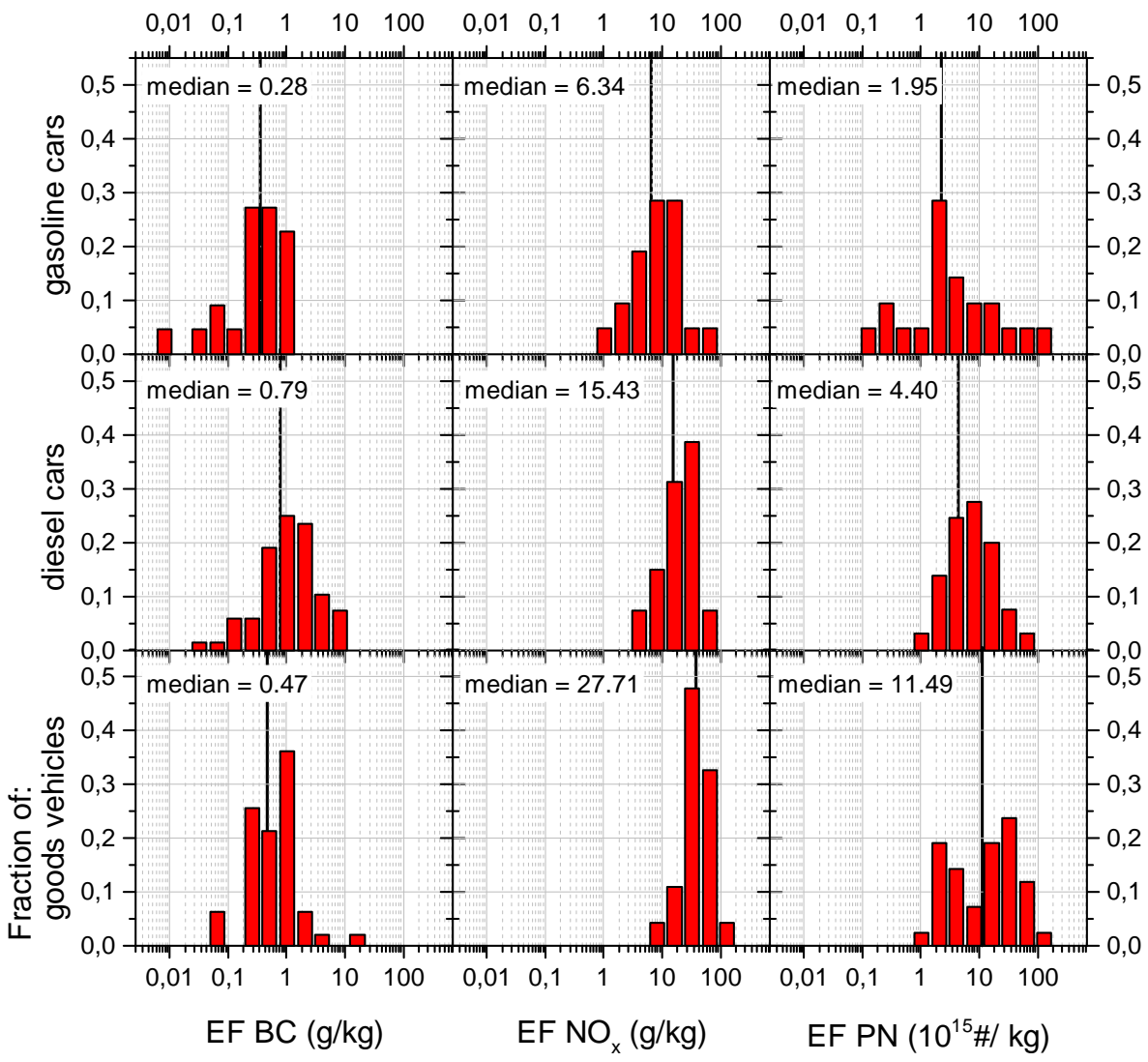

Figure 2. Black carbon (BC), particle number concentration $(\mathrm{PN})$ and $\mathrm{NO}_{x}$ emission factor $(\mathrm{EF})$ distributions for gasoline and diesel cars, light and heavy goods vehicles. Note the EF logarithmic scale.

in use, because an improved vehicle may be put on the market before the date when the new standard is enforced, or a vehicle that is compliant to the old standard may still be put to use 1 year after the new standard enforcement date (2001/116/EC European Communities, 2002). The vehicle age should reflect not only the deterioration of the engine and exhaust system, but also the technological advances made in engines and exhaust systems over the years due to stricter emission standards.

The results show some improvement for the three investigated pollutants (Figs. 3 and S3). For BC EFs the improvement is most evident for less than 5-year old diesel cars, where we can see a $60 \%$ drop in median values from 510 -year old diesel cars to those with age less than 5 years. This reduction most probably reflects the impacts of regulations to reduce the PM vehicle emissions from Euro 3 to Euro 4 by $50 \%$. The reduction was probably achieved with the increased use of diesel particle filters (DPF), which are commonly used in the post Euro 5 cars. We can also observe a $55 \%$ decrease in median BC EF of gasoline cars from the oldest ( 10 or older) to the newest group (5 years or less). These vehicles are less critical regarding PM emissions than diesel cars. However, due to increased PM emissions, and especially PN emissions, of direct injection gasoline cars, both of these parameters are limited in recent Euro emission standards. Our results show that compared to the newest diesel car category the gasoline cars have lower BC EF medians in all three age groups. We can observe a $41 \%$ decrease in $\mathrm{BC}$ EF median from goods vehicles older than 10 years to the 5-10-year category. Worryingly, the newest goods vehicles median BC EF increased by $34 \%$ in comparison to the 5-10year old group. Emission standards from Euro III to Euro IV for goods vehicles demanded PM emissions (in $\mathrm{g} \mathrm{kW}^{-1} \mathrm{~h}^{-1}$ ) to reduce 5 fold. Unlike passenger cars, the emission reduction of goods vehicles was achieved with SCR and not with DPF, and thus the soot emissions were not limited as efficiently.

In Fig. 3 (and Fig. S3) we observed a $67 \%$ decrease in goods vehicles PN EFs (in $10^{15} \mathrm{~kg}^{-1}$ ) from 5-10-year old vehicles to those that were in use for less than 5 years. This may indicate that either more agglomerated soot particles were being emitted or emissions of some of the particulate precursors had been reduced. Median PN EFs reduced by $67 \%$ from the oldest to the newest diesel car group. For gasoline cars the PN EFs varied the most within individual age groups, where individual vehicles with high emissions skewed the distribution. 


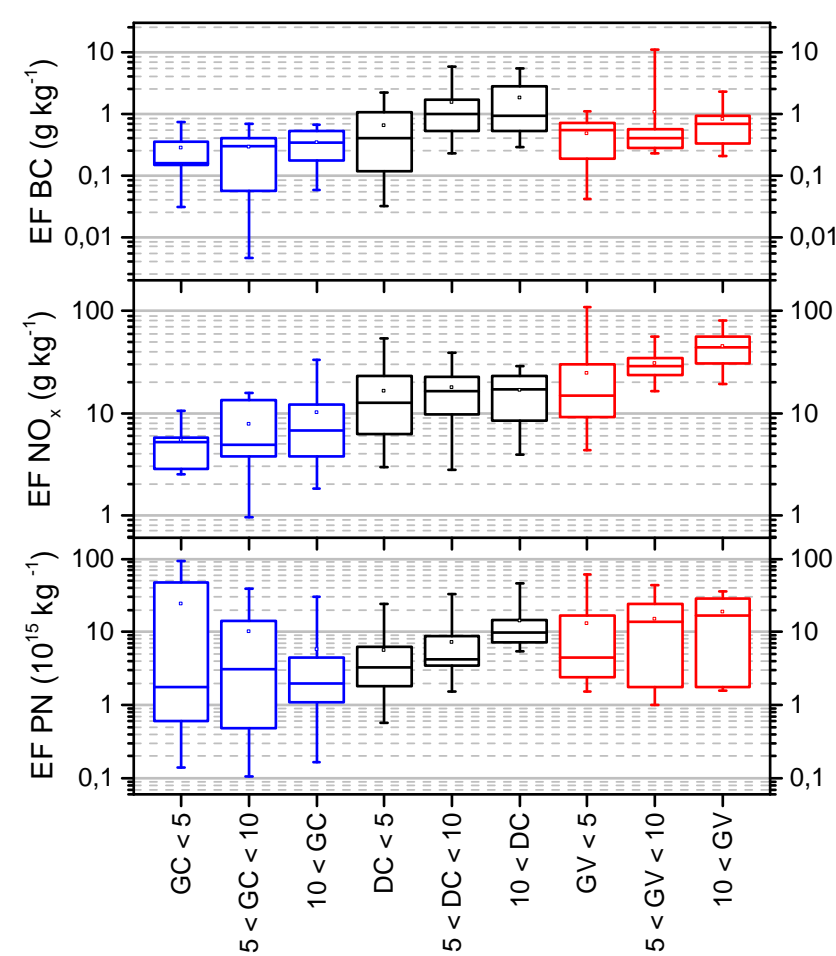

Figure 3. $\mathrm{BC}, \mathrm{NO}_{x}$ and $\mathrm{PN}$ EFs according to different vehicle categories and age group subcategories: gasoline passenger cars (GC, blue), diesel passenger cars (DC, black), and goods vehicles (GV, red). Note the EF logarithmic scale; same figure in linear scale can be found in Supplement Fig. S3.

In Fig. 3 (and Fig. S3) we can observe the gradual decrease of $\mathrm{NO}_{x}$ EFs from gasoline cars to diesel cars to goods vehicles, as it is also shown in Fig. 2, where also vehicles for which we did not get more detailed information were included. Goods vehicle $\mathrm{NO}_{x}$ EFs are showing an appreciable decrease in average and median values from the oldest to newest age group (50 and $70 \%$ respectively), which we postulate is due to increased use of SCR in newer post Euro V vehicles, which can effectively reduce $\mathrm{NO}_{x}$ emissions. When separated by age, we can see that now both $\mathrm{NO}_{x}$ and BC EF correlate better to some of the previously published studies (Table 7). The 10 year or older goods vehicles ( $\mathrm{BC}$ and $\mathrm{NO}_{x}$ EF respectively $0.7,43.95 \mathrm{~g} \mathrm{~kg}^{-1}$, please see Figs. 3 and S3) relate better with Wang et al. (2012), Chongqing EFs; and our less than 5-year old goods vehicles (median $\mathrm{BC}$ and $\mathrm{NO}_{x} \mathrm{EF}$, respectively $0.55,13.37 \mathrm{~g} \mathrm{~kg}^{-1}$ ) relate better with the most recent situation reported in the US for high cargo routes in California (I-710) by Hudda et al. (2013).

Diesel cars' maximum $\mathrm{NO}_{x}$ EFs increased in the newest group but the median of the group decreased by $24 \%$ in comparison to 5-10-year old diesel cars. $\mathrm{NO}_{x}$ emission standards for diesel and gasoline cars were introduced with the Euro 3 standard. We could observe a reduction of gasoline car median $\mathrm{NO}_{x}$ EF from those in use for over 10 years to those in use for 5-10 years. At this time the use of the three-way catalysts was common in the market and according to our results efficient in reducing $\mathrm{NO}_{x}$ emissions. The median did not reduce further for diesel cars that were in use for less than 5 years but the average value did. The decrease of emissions is smaller than we would expect it to be according to the newer European emission standards. We postulate that this is because the emissions of Euro 5 diesel cars were achieved with DPF, not including de- $\mathrm{NO}_{x}$ devices, in such instances driving that would be more aggressive than NEDC would not reflect more stringent $\mathrm{NO}_{x}$ Euro emission standards in real-world driving. In the study of Carslaw and Rhys-Tyler (2013), they found a satisfactory reduction of average $\mathrm{NO}_{x}$ $\mathrm{EF}$ only for gasoline cars but not for diesel cars.

Carslaw and Rhys-Tyler found an influence of vehicle manufacturer on $\mathrm{NO}_{x}$ EFs for Euro 4/5; this could potentially explain the skewed $\mathrm{NO}_{x}$ EF distribution observed in our fleet, if some of the manufacturers would be disproportionally represented. However, Carslaw and Rhys-Tyler did not reveal the brands that produce lower EF values; and our sample size is too small compared to the number of manufacturers for us to consider debating such trends in our fleet.

The reason the EF distributions are skewed and some an order of magnitude higher than the rest may be because, at the time of our measurements, these cars were somehow compromised, e.g., not well maintained, or frequently operating in transient conditions that favored high-pollutant emissions. On-road measurements of individual in-use vehicle fleets can provide useful information about the fleet emissions by exactly including such vehicles.

\subsection{Emission factors according to maximum net engine power and maximum net engine power to vehicle weight ratio}

In addition to the information about the vehicle engine type, their category and the date of first use, the registration database also provided information about the engine's maximum net power and vehicle curb weight. We present in this section the EFs sorted according to the engine maximum net power and the ratio of engine's maximum net power to vehicle's curb weight. Here, we do not use the same vehicle groups as in the previous subchapter. Rather we separated the vehicles into gasoline and diesel engines and then further according to different size bins for both engine maximum net power and maximum net power to weight ratio. The sizes of the bins were determined in a way that a single bin size would not include a disproportionally large number of vehicles and that each bin would have enough vehicles for a statistical presentation. There are also some gaps between the adjacent bins; this is because there were no vehicles in that range. The results are shown in Figs. 4 and S4.

When EF are sorted by a vehicle's engine maximum net power, we can see that diesel engines in the lowest maximum net power bin (less than $70 \mathrm{~kW}$ ) feature highest median BC 


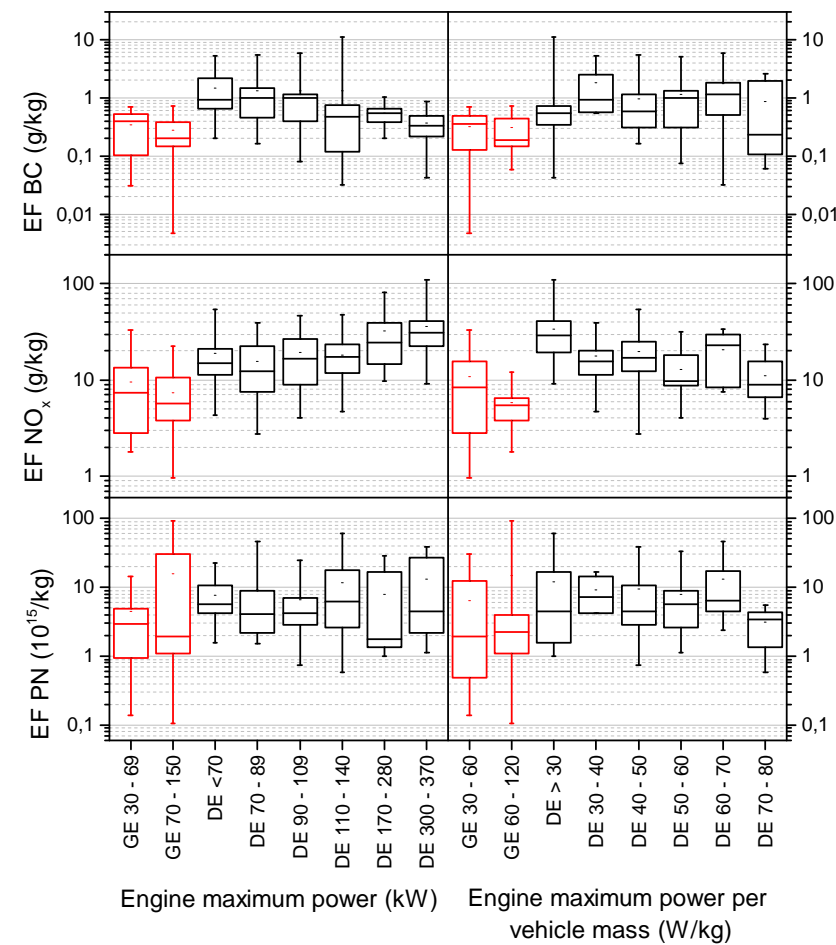

Figure 4. $\mathrm{BC}, \mathrm{NO}_{x}$ and $\mathrm{PN}$ Efs according to engine power (left) and power per mass (right); red boxes present gasoline engines (GE) and black boxes present all diesel engines (DE) regardless of their vehicle category. Note the EFs are on logarithmic scale; same figure in linear scale can be found in Supplement Fig. S4.

EFs and that the more powerful diesel engines feature lower $\mathrm{BC}$ EFs. The trend is reversed for $\mathrm{NO}_{x} \mathrm{EF}$, where more powerful larger vehicles feature higher $\mathrm{NO}_{x}$ EF. There is an exception for $\mathrm{NO}_{x} \mathrm{EF}$ in the least powerful diesel group, which feature relatively high $\mathrm{NO}_{x}$ EF compared to the adjacent engine power bins.

The ratio of maximum engine power to vehicle curb weight can give a rough estimate of the engine load under which the vehicle has to operate in normal driving conditions. Large trucks have high vehicle mass but low maximum net power to vehicle mass ratio. Smaller vehicles have smaller mass but higher maximum net power to vehicle mass ratios, and for the smallest vehicles the ratio again decreases. A vehicle with lower maximum net power to mass ratio driven in similar driving conditions and with a similar driver behavior would have its engine operating at higher loads leading to higher in-cylinder temperatures. Operation at higher in-cylinder temperatures would result in more thermic $\mathrm{NO}_{x}$. This trend in $\mathrm{NO}_{x}$ can be observed in Figs. 4 and S4 for both diesel and gasoline engines, where we can see that vehicles with low power to mass ratio produce higher $\mathrm{NO}_{x} \mathrm{EF}$ and vehicles with high power to mass ratio produce lower $\mathrm{NO}_{x}$ EF. For BC and PN EF the trend is not as clear as it is for $\mathrm{NO}_{x}$, it could be described as a gradual increase of
EF from low to high power to mass ratios but in the highest power to mass ratio bin the median BC and PN EF drop.

We separated the gasoline vehicles into two groups for each observed parameter. The differences between gasoline vehicle categories are difficult to observe. We postulate this is because we were only operating with cars and the change in the vehicle mass and mass to power ratio was smaller than it was for the vehicles with diesel engines which included trucks.

\subsection{Contribution of high emitters to the measured fleet}

The contribution of high emitters to the measured vehicle fleet was calculated as cumulative emissions. To exclude large differences in fuel consumption between trucks and cars, we calculated high emitter contribution separately for goods vehicles, gasoline cars and diesel cars. The cumulative emission distribution of our vehicle fleet was calculated for vehicles from highest to lowest emitters as it was previously done in similar studies (Ban-Weiss et al., 2009; Dallmann et al., 2012; Wang et al., 2011, 2012). The results in Fig. 5 show that $25 \%$ of the highest-emitting vehicles in each vehicle category produce 50 to $65 \%$ of $\mathrm{BC}$ emissions, 47 to $55 \%$ of $\mathrm{NO}_{x}$ emissions and $61-87 \%$ of $\mathrm{PN}$ emissions. The high contributions of super emitters are the statistical cause of the non-symmetrical distributions and are responsible for the mismatch between the median and the average EF values. Excluding high emitting vehicles or improving their emission rates by retrofitting them with additional after treatment devices, such as the case in the Port of Oakland, US (Dallmann et al., 2011) can decrease traffic emissions.

\section{Conclusions}

During the measurement campaign the $\mathrm{BC}, \mathrm{PN}$ and $\mathrm{NO}_{x} \mathrm{EFs}$ for 139 different vehicles were successfully determined. The sample fleet statistics were compared to Eurostat data for Slovenia and Europe. An excellent agreement between the composition of the average European and Slovenian car fleet, and the car sample fleet sampled in this campaign was found. The main results of this research are the first reported on-road $\mathrm{BC}$ EF for diesel cars, and first $\mathrm{BC}, \mathrm{PN}$ and $\mathrm{NO}_{x} \mathrm{EF}$ for passenger cars measured with the on-road chasing technique. In order to compare the results of this study to previous ones, EFs of goods vehicles were also determined. EF distributions for $\mathrm{BC}, \mathrm{PN}$ and $\mathrm{NO}_{x}$ were presented for three vehicle groups: diesel cars, gasoline cars and goods vehicles. Differences between the EF frequency distributions of the three vehicle categories for all three investigated pollutants were observed, the most important being the highest median BC $\mathrm{EF}$ value of diesel cars, and an increase in $\mathrm{NO}_{x}$ EFs from the least powerful to more powerful diesel vehicles.

The results of this study were compared to the results of previous studies that used similar methods. The median BC 

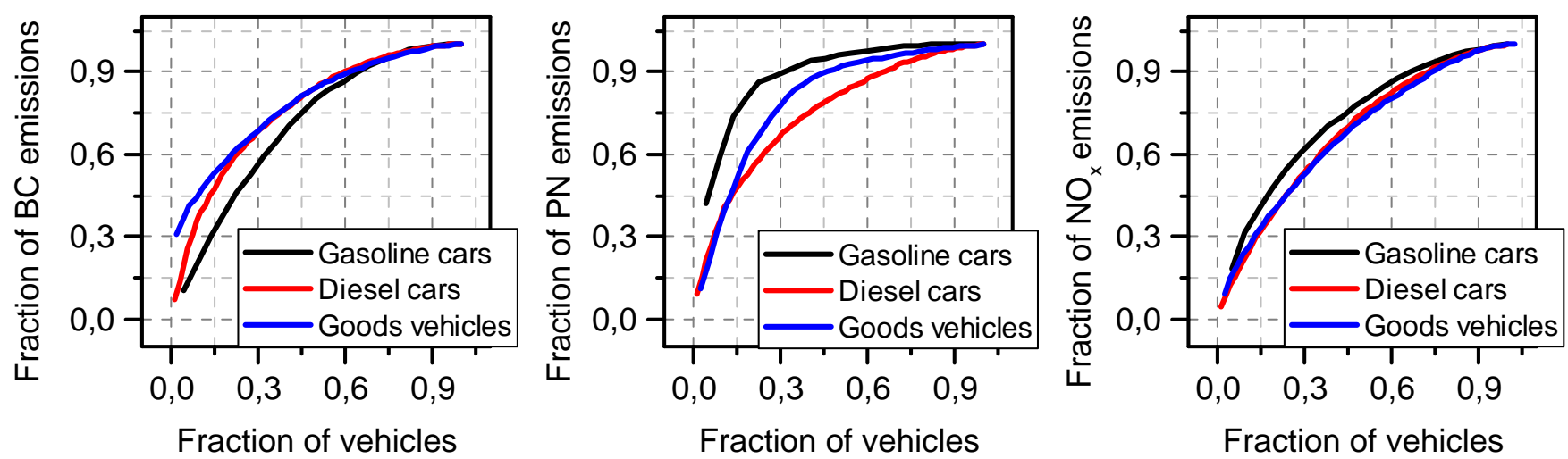

Figure 5. Cumulative distribution of all vehicle emissions. Fractions of vehicles are distributed from highest to lowest emitting vehicles. The result shows that $10 \%$ of vehicles contribute about a half of total $\mathrm{BC}$ and $\mathrm{NO}_{x}$ emissions.

EFs for the diesel cars $\left(0.79 \mathrm{~g} \mathrm{~kg}^{-1}\right)$ determined in this study is similar to the HGV EFs mean reported by Dallmann et al. (2011) and Wang et al. (2012), where vehicles were subject to less strict emission regulations. The goods vehicles' BC EF median determined here resembles the EFs determined for vehicles subject to stricter emission standards. The goods vehicle median $\mathrm{NO}_{x}$ EF reported in this study resembles those determined by Dallmann et al. (2011) and Shorter et al. (2005).

The median BC EF value of newer diesel and gasoline cars (less than 5 years) is lower than the value for the older car categories. For the goods vehicles it lies between the medians of the two older goods vehicles groups. Contrary to $\mathrm{BC} \mathrm{EF}$, goods vehicles showed a significant $73 \%$ decrease in the $\mathrm{NO}_{x} \mathrm{EF}$ median values from vehicles that were in use for over 10 to those in use for less than 5 years. We postulate this is because different after-treatment approaches were used for passenger cars and goods vehicles. PN EF median values decreased for vehicles in use for less than 5 years in all three vehicle groups compared to older ones, but unfortunately the span of PN EFs of goods vehicles and gasoline cars increased. We attribute the decreases to advances made in engine operation and exhaust after treatment devices.

The contribution of highly emitting vehicles was calculated and, as in previous studies (e.g. Ban-Weiss et al., 2009; X. Wang et al., 2015; J. M. Wang et al., 2012), a small number of vehicles $(25 \%)$ was found to disproportionately contribute to the total fleet emissions (47 to $87 \%$ ). The exclusion of high emitters by retrofitting old vehicles with aftertreatment devices and encouraging the sale of new vehicles through the exchange of older vehicles, has shown to be an effective measure to reduce vehicle emission rates (Dallmann et al., 2011) locally. Unfortunately, the older vehicles might be sold in countries beyond the reach of the EU regulations, and would still have a negative impact on air quality and the climate elsewhere.

The methodology used in this study is a relatively simple and efficient approach for monitoring emissions of the in-use vehicle fleet, and investigating the effectiveness of emission reduction measures (also shown in Dallmann et al., 2011; Wang et al., 2011). Real-world measurements are important because individual vehicle emissions depend not only on the vehicle type approval at the time it is put on the market, but are also on their maintenance and the driving conditions.

\section{The Supplement related to this article is available online at doi:10.5194/acp-15-11011-2015-supplement.}

Acknowledgements. This research was part founded by European Social found (SPIRIT, contract no. P-MR-10/04). The authors would like to acknowledge Slovenian Ministry of Infrastructure and Spatial Planning for providing the vehicle registration information; TSI for lending their instrument; Polona Ježek for lending her vehicle; Anže Buh for driving the mobile station and discussing some of the vehicle technologies; and to our colleagues at Aerosol d.o.o. for continuing technical support and discussion. I. Ježek and G. Močnik are employed in Aerosol d.o.o. where the Aethalometer was developed and is manufactured.

Edited by: J. Allan

\section{References}

ACEA: The Automobile Industry Pocket Guide, ACEA Commun. Dep., 2012.

Ajtay, D., Weilenmann, M., and Soltic, P.: Towards accurate instantaneous emission models, Atmos. Environ., 39, 2443-2449, doi:10.1016/j.atmosenv.2004.03.080, 2005.

Ban-Weiss, G. A., Lunden, M. M., and Kirchstetter, T. W.: Measurement of Black Carbon and Particle Number Emission Factors from Individual Heavy-Duty Trucks, Environ. Sci. Technol., 43, 1419-1424, 2009.

Bishop, G. A. and Stedman, D. H.: A decade of on-road emissions measurements, Environ. Sci. Technol., 42, 1651-1656, 2008. 
Bishop, G. A., Stedman, D. H., and Ashbaugh, L.: Motor vehicle emissions variability, J. Air Waste Manage. Assoc., 46, 667-675, 1996.

Bond, T. C., Doherty, S. J., Fahey, D. W., Forster, P. M., Berntsen, T., DeAngelo, B. J., Flanner, M. G., Ghan, S., Kärcher, B., Koch, D., Kinne, S., Kondo, Y., Quinn, P. K., Sarofim, M. C., Schultz, M. G., Schulz, M., Venkataraman, C., Zhang, H., Zhang, S., Bellouin, N., Guttikunda, S. K., Hopke, P. K., Jacobson, M. Z., Kaiser, J. W., Klimont, Z., Lohmann, U., Schwarz, J. P., Shindell, D., Storelvmo, T., Warren, S. G., and Zender, C. S.: Bounding the role of black carbon in the climate system: A scientific assessment, J. Geophys. Res.-Atmos., 118, 5380-5552, doi:10.1002/jgrd.50171, 2013.

Canagaratna, M. R., Jayne, J. T., Ghertner, D. a., Herndon, S., Shi, Q., Jimenez, J. L., Silva, P. J., Williams, P., Lanni, T., Drewnick, F., Demerjian, K. L., Kolb, C. E., and Worsnop, D. R.: Chase Studies of Particulate Emissions from in-use New York City Vehicles, Aerosol Sci. Technol., 38, 555-573, doi:10.1080/02786820490465504, 2004.

Carslaw, D. C. and Rhys-Tyler, G.: New insights from comprehensive on-road measurements of $\mathrm{NO}_{x}, \mathrm{NO}_{2}$ and $\mathrm{NH}_{3}$ from vehicle emission remote sensing in London, UK, Atmos. Environ., 81, 339-347, doi:10.1016/j.atmosenv.2013.09.026, 2013.

Dallmann, T. R., Harley, R. A., and Kirchstetter, T. W.: Effects of diesel particle filter retrofits and accelerated fleet turnover on drayage truck emissions at the port of Oakland, Environ. Sci. Technol., 45, 10773-10779, 2011.

Dallmann, T. R., Demartini, S. J., Kirchstetter, T. W., Herndon, S. C., Onasch, T. B., Wood, E. C., and Harley, R. A.: On-road measurement of gas and particle phase pollutant emission factors for individual heavy-duty diesel trucks, Environ. Sci. Technol., 46, 8511-8518, 2012.

Dallmann, T. R., Onasch, T. B., Kirchstetter, T. W., Worton, D. R., Fortner, E. C., Herndon, S. C., Wood, E. C., Franklin, J. P., Worsnop, D. R., Goldstein, A. H., and Harley, R. A.: Characterization of particulate matter emissions from on-road gasoline and diesel vehicles using a soot particle aerosol mass spectrometer, Atmos. Chem. Phys., 14, 7585-7599, doi:10.5194/acp-14-75852014, 2014.

Drinovec, L., Mocnik, G., Zotter, P., Prévôt, A. S. H., Ruckstuhl, C., Coz, E., Rupakheti, M., Sciare, J., Müller, T., Wiedensohler, A., and Hansen, A. D. A.: The "dual-spot" Aethalometer: an improved measurement of aerosol black carbon with realtime loading compensation, Atmos. Meas. Tech., 8, 1965-1979, doi:10.5194/amt-8-1965-2015, 2015.

European Communities: Commission Directive 2001/116/EC of 20 December 2001 adapting to technical progress Council Directive 70/156/EEC on the approximation of the laws of the Member States relating to the type-approval of motor vehicles and their trailers, Off. J. Eur. Communities, 18, 1-114, 2002.

EEA: Monitoring $\mathrm{CO}_{2}$ emissions from new passenger cars in the EU: summary of data for 2011, European Environment Agency, Copenhagen, Denmark, 2013a.

EEA: Monitoring $\mathrm{CO}_{2}$ emissions from new passenger cars in the EU: summary of data for 2012 - European Environment Agency (EEA), EEA Publ., Copenhagen, Denmark, 2013b.

EEA: EMEP/EEA air pollutant emission inventory guidebook 2013 - Technical guidance to prepare national emission inventories -
European Environment Agency (EEA), EEA Publ., Copenhagen, Denmark, doi:10.2800/92722, $2013 \mathrm{c}$.

European Parliament: Regulation (EU) No 540/2014 on the sound level of motor vehicles and of replacement silencing systems, and amending Directive 2007/46/EC and repealing Directive 70/157/EEC, European parliament and of the council., Off. J. Eur. Union, L 158, 131-195, 2014.

Franco, V., Kousoulidou, M., Muntean, M., Ntziachristos, L., Hausberger, S., and Dilara, P.: Road vehicle emission factors development: A review, Atmos. Environ., 70, 84-97, doi:10.1016/j.atmosenv.2013.01.006, 2013.

Hansen, A. D. A. and Rosen, H.: Individual measurements of the emission factor of aerosol black carbon in automobile plumes, J. Air Waste Manage. Assoc., 40, 1654-1657, 1990.

Herndon, S. C., Shorter, J. H., Zahniser, M. S., Wormhoudt, J., Nelson, D. D., Demerjian, K. L., and Kolb, C. E.: Real-Time Measurements of $\mathrm{SO}_{2}, \mathrm{H}_{2} \mathrm{CO}$, and $\mathrm{CH}_{4}$ Emissions from In-Use Curbside Passenger Buses in New York City Using a Chase Vehicle, Environ. Sci. Technol., 39, 7984-7990, 2005.

Heywood, J. B.: Internal Combustion Engine Fundamentals, McGraw-Hill Inc., 1988.

Hudda, N., Fruin, S., Delfino, R. J., and Sioutas, C.: Efficient determination of vehicle emission factors by fuel use category using on-road measurements: downward trends on Los Angeles freight corridor I-710, Atmos. Chem. Phys., 13, 347-357, doi:10.5194/acp-13-347-2013, 2013.

Huss, A., Maas, H., and Hass, H.: Well-to-wheels analysis of future automotive fuels and powertrains in the European context, Tankto-wheels (TTW) report, version 4, EC Joint Research Centre, Luxembourg, doi:10.2788/40409, 2013.

Janssen, N. A. H., Gerlof-Nijland, M. E., Lanki, T., O, S. R., Cassee, F., Gerard, H., Fischer, P., Brunekreef, B., and Krzyzanowski, M.: Health effects of Black Carbon, WHO Regional Office for Europe, Bonn, 2012.

Ježek, I., Drinovec, L., Ferrero, L., Carriero, M., and Močnik, G.: Determination of car on-road black carbon and particle number emission factors and comparison between mobile and stationary measurements, Atmos. Meas. Tech., 8, 43-55, doi:10.5194/amt8-43-2015, 2015.

Kim, J., Bauer, H., Dobovičnik, T., Hitzenberger, R., Lottin D., Ferry, D., and Petzold, A.: Assessing Optical Properties and Refractive Index of Combustion Aerosol Particles Through Combined Experimental and Modeling Studies, Aerosol Sci. Technol., 49, 340-350, doi:10.1080/02786826.2015.1020996, 2015.

Kittelson, D., Watts, W., and Johnson, J.: On-road and laboratory evaluation of combustion aerosols - Part1: Summary of diesel engine results, J. Aerosol Sci., 37, 913-930, 2006.

Mock, P., German, J., and Icct, A. B.: From Laboratory to Road: A Comparison of official and real-world fuel consumption and $\mathrm{CO}_{2}$ values for cars in the EU and US, May, available at: http://www.theicct.org/sites/default/files/publications/ICCT_ LabToRoad_20130527.pdf (last access: 25 November 2014), 2013.

Ning, Z., Chan, K. L., Wong, K. C., Westerdahl, D., Močnik, G., Zhou, J. H., and Cheung, C. S.: Black carbon mass size distributions of diesel exhaust and urban aerosols measured using differential mobility analyzer in tandem with Aethalometer, Atmos. Environ., 80, 31-40, doi:10.1016/j.atmosenv.2013.07.037, 2013. 
Perrone, M. G., Carbone, C., Faedo, D., Ferrero, L., Maggioni, A., Sangiorgi, G., and Bolzacchini, E.: Exhaust emissions of polycyclic aromatic hydrocarbons, n-alkanes and phenols from vehicles coming within different European classes, Atmos. Environ., 82, 391-400, doi:10.1016/j.atmosenv.2013.10.040, 2014.

Schneider, J., Kirchner, U., Borrmann, S., Vogt, R., and Scheer, V.: In situ measurements of particle number concentration, chemically resolved size distributions and black carbon content of traffic-related emissions on German motorways , rural roads and in city traffic, Atmos. Environ., 42, 4257-4268, doi:10.1016/j.atmosenv.2008.01.014, 2008.

Sharma, M., Kumar, A., and Bharathi, K. V. L.: Characterization of exhaust particulates from diesel engine, Atmos. Environ., 39, 3023-3028, doi:10.1016/j.atmosenv.2004.12.047, 2005.

Shorter, J. H., Herndon, S. C., Zahniser, M. S., Nelson, D. D., Wormhoudt, J., Demerjian, K. L., and Kolb, C. E.: Real-time measurements of nitrogen oxide emissions from in-use New York City transit buses using a chase vehicle, Environ. Sci. Technol., 39, 7991-8000, 2005.

Sorensen, C. M.: Light Scattering by Fractal Aggregates: A Review, Aerosol Sci. Technol., 35, 648-687, 2001.

United Nations: Addendum 84: Regulation No. 85, 2013.
USEPA: Code federal regulations - Title 40: Protection of environment Part 86, Electronic Code of Federal Regulations, available at: http://www.ecfr.gov/cgi-bin/text-idx?tpl=/ecfrbrowse/ Title40/40cfr86_main_02.tpl (last access: 30 September 2015), 2010.

Wang, J. M., Jeong, C.-H., Zimmerman, N., Healy, R. M., Wang, D. K., Ke, F., and Evans, G. J.: Plume-based analysis of vehicle fleet air pollutant emissions and the contribution from high emitters, Atmos. Meas. Tech., 8, 3263-3275, doi:10.5194/amt8-3263-2015, 2015.

Wang, X., Westerdahl, D., Wu, Y., Pan, X., and Zhang, K. M.: Onroad emission factor distributions of individual diesel vehicles in and around Beijing, China, Atmos. Environ., 45, 503-513, doi:10.1016/j.atmosenv.2010.09.014, 2011.

Wang, X., Westerdahl, D., Hu, J., Wu, Y., Yin, H., Pan, X., and Zhang, K. M.: On-road diesel vehicle emission factors for nitrogen oxides and black carbon in two Chinese cities, Atmos. Environ., 46, 45-55, doi:10.1016/j.atmosenv.2011.10.033, 2012.

Weingartner, E., Keller, C., and Stahel, W.: Aerosol emission in a road tunnel, Atmos. Environ., 31, 451-462, 1997. 